\title{
Computational fluid dynamics investigation on total resistance coefficient of a high-speed "deep-V" catamaran in shallow water
}

\author{
A. Fitriadhy, S. A. Azmi, N. Aqilah Mansor, and N. Adlina Aldin \\ Program of Maritime Technology, School of Ocean Engineering, Universiti Malaysia \\ Terengganu, Malaysia \\ *Email: naoe.afit@gmail.com \\ Phone: +6096683856; Fax: +6096683193
}

\begin{abstract}
A reliable investigation that allows an accurate prediction of the total resistance coefficient of a high-speed" deep-V" catamaran in shallow water is obviously required. The Computational Fluid Dynamic simulation proposed approach is aimed to attain this precise outcome, while a hydrodynamic description of the rationale underlying behind the results is explained. Several effects of lateral separation ratios $(S / L)$ and longitudinal staggered position $(R / L)$ against a wide range of Froude numbers $(F r)$ from 0.5 to 1.0 were considered. The results revealed that the general increase in $F r$ is proportional to the increase of total resistance. In contrast, the increase of lateral separation ratios dealt with less total resistance coefficient, where the sufficient reduction of $\mathrm{C}_{\mathrm{T}}$ was about $11 \%$ as the $F r$ increase from 0.5 to 0.6 for $S / L=0.3$. Regardless of $R / L$ ratios, the results showed the subsequent increase of $\mathrm{Fr}$ from 0.5 to 1.0 was also proportional to the total resistance, where the maximum increase of $\mathrm{R}_{\mathrm{T}}$ was about $21 \%$ as the $F r$ increase from 0.6 to 0.7 . In addition, the increase of $R / L$ ratios has led to sufficient increment of $C_{\mathrm{T}}$ by $1.5 \%$ as the $F r$ increase from 0.9 to 1.0. Generally, the increase of $\mathrm{S} / \mathrm{L}$ and $\mathrm{R} / \mathrm{L}$ ratios have similar effects on the total resistance characteristics. This CFD simulation results are very useful as preliminary data for the ship resistance, which is mainly required for predicting a ship powering accurately.
\end{abstract}

Keywords: Catamaran; total resistance coefficient; lateral separation; staggered position; Froude number.

\section{INTRODUCTION}

A catamaran ship is one of the multi-hull vessel types that geometrically consist of two demihulls. This inherent configuration offers some advantages as compared to the monohull ship types, in view of its design feasibility and operation [1], large deck areas of around $20 \%$ and $40 \%$ greater than a corresponding monohull and have better stability characteristics which enhance seakeeping characteristics in moderate sea states, as reported by Hadler et al. [2] and [3]. Scientific interest on the resistance of shallow water effect existed with the growth of ship size and added shipping routes congestion. Prakash and Chandra [4] stated that the resistance of ship in shallow water is quite sensitive and the flow around the hull changes appreciably. Therefore, a comprehensive understanding on the shallow characteristic in respect to peculiar added hydrodynamic forces is obviously required to obtain a more appropriate prediction of the power requirement [5]. The sinkage and trim in very shallow water can set an upper limit to the speed so that the 
ship can operate without grounding. The wave patterns, created by the moving ship, change in shallow water and lead to change in the wave making resistances. Jachowski [6] stated that during ship motion in shallow water there are phenomenon when the clearance decrease. There are different flow velocities and change in water pressure along the hull. In shallow water there is a small pressure value at the midship as compared to the deep water condition and a bigger pressure value exists in the ship bow and aft parts . According to pressure distribution, the water level increases in the ship bow and aft but decreases in midship. Water region simulating shallow water conditions of depth $(\mathrm{H})$ to draft ( $\mathrm{T})$ ratio is $\mathrm{H} / \mathrm{T}=1.2$ and $\mathrm{H} / \mathrm{T}=1.5$. According to Saha et al. [7], a ship that is moving in shallow water have higher resistance. This is due to a higher pressure that is caused by the ship motion and change in stream velocities that past the ship surface. According to Havelock [8], the resistance in shallow water at low velocities is greater than that in deep water. As the velocity increase, the pressure at bottom of the ship will decrease and the resistance will increase. When the speed increases, the resistance increases to the maximum at certain critical velocity and then diminishes. Besides, in Moraes et al. [9], the research paper showed that water velocity around the hull increased in shallow water. It resulted in a higher drag that was comparable to a higher effective speed. The accelerating water can pull the vessel squat that can cause the ship to act as it has a higher displacement.

The demands for catamaran resistance predictions have set a real challenge for the naval architecture and, have become a primary requirement to be assessed, particularly in considering two aspects (i.e. speed and fuel consumption) for a higher efficiency of the ship operational cost. Since the last decade, considerable research papers were published to discuss the resistance characteristics of the catamaran. This is particularly true when one realises that the resistance behaviour of a catamaran is obviously different as compared to the typical monohull ships. Here, the basic reason is mainly because the presence of incident divergent waves that involve with the simultaneous wave fields interactions between two demihulls on the catamaran is generally a highly complex phenomenon and superposed non-linearly to induced the total resistance coefficients. The investigations of [10], [11], [12], [13], [14] and [15] were focused on the effects of the hull clearance or the lateral separation between two demihulls revealed that the change in lateral distance between two demihulls on the catamaran contributed a significant effect to the resistance components. To quantify the viscous effects on the ship resistance, the experimental NPL catamaran model in a wind tunnel showed that the viscous resistance had entirely increased due to the significant interference between two demihulls in close proximity [16]. This approach in particular, is relatively expensive, time-consuming and even impractical for various resistance test configurations. It is obvious that a reliable Computational fluid dynamics (CFD) approach has become a necessary aim to gain more accurate predictions of the total resistances that involve the dynamic interaction effects between two demihulls, both in various lateral separations and longitudinal staggered positions.

This paper presents a CFD simulation to predict the total resistance coefficient of a high-speed "deep- $V$ " catamaran in calm water. In presence of a strongly non-linear interaction between two demihulls, several parameters, such as effects of $S / L$ (the lateral separation ratio between two center-lines of the demihulls) and $R / L$ (the longitudinal staggered position ratio with respect to transom of the demihulls) on the total resistance of the catamaran at a wide range of Froude numbers ( 0.5 to 1.0$)$ were taken into account. The purpose of this study is to provide a prominent insight into dependency of $S / L$ and $R / L$ ratios on the total resistance coefficient of the high-speed "deep-V" catamaran. Since the necessary precision is attainable from the simulation model, the CFD approach can provide 
truly valuable outcomes by evaluating a hydrodynamic description that underlies the rationale behind the results explained. This is the main reason why the authors applied the CFD approach rather than by using the traditional numerical approach. A commercial CFD software, namely NUMECA FINE Marine 3.1-1, was utilised by applying the incompressible unsteady Reynolds-Averaged Navier Stokes equations (RANSE) in which RANSE and continuity equations are discretised by the finite volume method based on Volume of Fluid (VOF) to deal with the non-linear free surface. In addition, the computational domain, with adequate numbers of grid meshes (for demihull, symmetrical and staggered catamaran simulation models), was carefully determined before simulations. Basically, this is solved by means of a mesh independent study to select the optimal domain discretisation as is appropriately explained in Sub-section 3.3. Instead, a combination of the computational modelling with model tests had proved to be a very effective approach in investigating this type of problem.

\section{METHODS AND MATERIALS}

\section{Governing Equation}

The CFD flow solver on NUMECA FINE Marine 3.1-1 is based on the incompressible unsteady RANSE in which the solver applies the Finite Volume Method to build a spatial discretisation of the transport equations. In addition, the velocity field is obtained from the momentum equations and the pressure field is extracted from the mass conservation constraint, or continuity equation, which is transformed into a pressure equation. In the case of turbulent flows, additional transport equations for modelled variables are solved in a form similar to that of the momentum equations and they can be discretised and solved by using the same principles. Furthermore, the non-linear free surface flow is treated as the interface between air and water, which is assumed to be incompressible and isotropic Newtonian fluid.

\section{Conservation Equations}

The flow solver can deal with multi-phase flows and moving grids. In the multi-phase continuum, considering incompressible flow of viscous fluid under isothermal conditions, mass, momentum and volume fraction conservation equations can be expressed (by using the generalised form of Gauss' theorem) as:

$$
\begin{aligned}
& \frac{\partial}{\partial_{t}} \int_{S} \rho\left(\vec{U}-\vec{U}_{d}\right) \cdot \vec{n} d S=0 \\
& \frac{\partial}{\partial_{t}} \int_{V} \rho U_{i} d V+\int_{S} \rho U_{i}\left(\vec{U}-\vec{U}_{d}\right) \cdot \vec{n} d S=\int_{S}\left(\tau_{i j} I_{j}-p I_{i}\right) \cdot \vec{n} d S+\int_{V} \rho g_{i} d V \\
& \frac{\partial}{\partial_{t}} \int_{V} c_{i} d V+c_{i}\left(\vec{U}-\vec{U}_{d}\right) \cdot \vec{n} d S=0
\end{aligned}
$$

where $V$ is the control volume, bounded by the closed surface $S$ with a unit normal vector $\vec{n}$ directed outward that moves at the velocity $\vec{U}_{d}$ with a unit normal vector $\vec{n}$. The notation of $\vec{U}$ and $p$ represent the velocity and pressure fields, respectively. $\tau_{i j}$ and $g_{i}$ define the components of the viscous stress tensor and the gravity vector, respectively; whereas $I_{j}$ is a vector whose components vanish, except for the component $j$ which is equal to unity. $c_{i}$ is the $i^{t h}$ volume fraction for fluid $i$ and is used to distinguish the presence $\left(c_{i}=1\right)$ or the absence $\left(c_{i}=0\right)$ of $i^{t h}$ fluid. Since a volume fraction between 0 and 1 indicates the presence of a mixture, the value of $1 / 2$ is selected as a definition of the interface. 


\section{Turbulence Model}

In the current CFD simulation, we propose the SST k- $\omega$ (SST for shear-stress transport) model, which is available inside the ISIS-CFD solver code, where $k$ is the turbulent kinetic energy and $\omega$ is the specific dissipation rate. Menter [17], [18], Menter [19] and [20] reported that the SST k- $\omega$ model combines several desirable elements of existing two-equation models. [21] and [22] highlighted that the SST $k-\omega$ model here is set to improve the predictions obtained with algebraic mixing-length models to develop a local model for complex flows, and to provide a simpler alternative for two-equation turbulence models. The two transport equations of the model are defined below with a blending function $F_{1}$ for the model coefficients of the original $\omega$ and $\varepsilon$ model equations and are written as:

$$
\begin{gathered}
\frac{\partial \rho K}{\partial t}+\frac{\partial}{\partial x_{j}}\left(\rho U_{j} K-\left(\mu+\sigma_{k} \mu_{t}\right) \frac{\partial K}{\partial x_{j}}\right)=\tau_{i j} S_{i j}-\beta^{*} \rho \omega K \\
\frac{\partial \rho \omega}{\partial t}+\frac{\partial}{\partial x_{j}}\left(\rho U_{j} \omega-\left(\mu+\sigma_{\omega} \mu_{t}\right) \frac{\partial \omega}{\partial x_{j}}\right)=P_{\omega}-\beta \rho \omega^{2}+2\left(1-F_{1}\right) \frac{\rho \sigma_{\omega 2}}{\omega} \frac{\partial K}{\partial x_{j}} \frac{\partial \omega}{\partial x_{j}}
\end{gathered}
$$

where the last source term of Eq. (5) represents the cross-diffusion term that appears in the transformed $\omega$-equation from the original $\varepsilon$-equation. Menter and Rumsey [23] noted that the production term of $\omega$ is sometimes approximated as proportional to the absolute value of vorticity:

$$
P_{\omega}=2 \gamma \rho\left(S_{i j}-\frac{\omega S_{n n} \delta_{i j}}{3}\right) S_{i j} \cong \gamma \rho \Omega^{2}
$$

The auxiliary blending function $F_{1}$, designed to blend the model coefficients of the original $\mathrm{k}-\omega$ model in boundary layer zones with the transformed $\mathrm{k}-\varepsilon$ model in freeshear layer and free-stream zones, is defined as follows:

$$
F_{1}=\max \left\{\left[\min \left\{\max \left\{\frac{\sqrt{K}}{0.09 d \omega}, \frac{500 \mu}{\rho d^{2} \omega}\right\}, \frac{4 \varnothing \sigma_{\omega 2} k}{C D_{k \omega} d^{2}}\right\}\right]^{4}\right\}
$$

where $C D_{k \omega}=\max \left\{\frac{2 \rho \sigma_{\omega 2}}{\omega} \frac{\partial K}{\partial X_{J}} \frac{\partial \omega}{\partial X_{J}}, 10^{-20}\right\}$. Here, $C D_{k \omega}$ is the cross-diffusion in the $\mathrm{k}$ $-\omega$ model.

It should be noted here that when calculating the turbulence quantities, it is important to consider an appropriate cell meshing size. To properly capture it, a sufficient number of grid points inside the boundary layer is essential. Here, an appropriate estimation of the cell meshing size $y_{\text {wall }}$ for Navier-Stokes simulations, including turbulence, depends on the local Reynolds number, which is computed based on the wall variable $y^{+}$. This is a $y^{+}$dimensionless parameter representing local Reynolds number in the near wall region. Referring to [24] the value of $y^{+}$value associated with the first node near the wall will be referred to as $y_{1}^{+}$, where the equation of $y_{1}^{+}$can be written as:

$$
y_{1}^{+}=\frac{\rho u_{\tau} y_{\text {wall }}}{\mu}
$$

where $u_{\tau}$ is the friction velocity, $u_{\tau}=\sqrt{\frac{\tau_{\text {wall }}}{\rho}}=\sqrt{\frac{1}{2} \rho\left(V_{\text {ref }}\right)^{2} C_{f}}$. It is clear that the value of $y_{\text {wall }}$ depends on the value of $y_{1}^{+}$.

In addition, the estimation for $y_{\text {wall }}$ as a function of a desired $y_{1}^{+}$value is obtained by using a truncated series solution of the Blasius Equation, as written in Eq. (9). 


$$
y_{\text {wall }}=6\left(V_{\text {ref }} / v\right)^{-7 / 8}\left(L_{r e f} / 2\right)^{1 / 8} y_{1}^{+}
$$

Note that the reference velocity, $V_{\text {ref }}$, can be taken from the body velocity. The reference length, $L_{r e f}$, should be based on the body length since an estimation of the boundary layer thickness is implied in this calculation. For instance, in the case of a marine simulation, one could use the boat length, or the so-called length between perpendiculars, as reference length. This refers to the length of a vessel along the waterline from the forward surface of the stem, or main bow perpendicular member, to the after surface of the stern-post, or main stern perpendicular member.

\section{Total Resistance Prediction of a Ship}

Based on the traditional resistance theory, the total resistance of a ship can be expressed in Equation. (10) as the sum of the frictional resistance $\left(R_{F}\right)$ and the residual resistance or called here as the pressure resistance $\left(R_{P}\right)$.

$$
R_{T}=R_{F}+R_{P}
$$

where the coefficient of the total resistance is expressed as [11] [25]:

$$
C_{T}=\frac{R_{T}}{0.5 \times \rho \times W S A \times V s^{2}}
$$

where, $R_{T}$ is the dimensional total resistance, $\rho$ is the water density, WSA is the wetted surface area of the ship at rest and $V_{S}$ is the forward ship speed.

\section{Simulation Condition}

\section{Principal Data of Ship}

In the current CFD simulation, a 3D model and principal dimension of the high-speed "deep-V" catamaran, which is composed of two demihulls, are presented in Figure 1 and Table 1, respectively.

\section{Simulation Parameter}

Figure 2 shows several effects of $S / L$ (the lateral separation ratio between two centerlines of the demihulls) and $R / L$ (represents the longitudinal staggered position ratio with respect to the demihulls transom) at a wide range of Froude numbers $(F r)$. Correspondingly, the details of the simulation parameter for predicting the total resistance with regards to various configurations of the high-speed "deep-V" catamaran are summarised in Table 2.

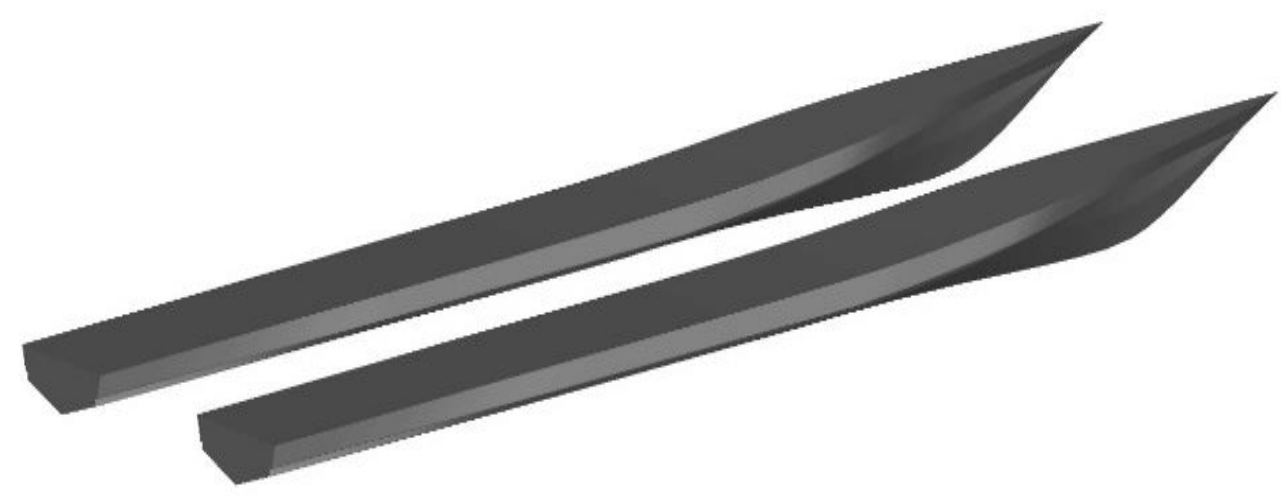

Figure 1. 3D model of a high speed "deep-V” catamaran model. 


\section{Computational Domain and Meshing Generation}

The computational domain of the catamaran model associated with the unstructured hexahedral meshes is shown in Figure 3. An extra local refinement of the mesh was added around the free surface to capture the waves that are generated by the catamaran hull during computation. In addition, the local box refinement was employed surrounding the global meshed computational domain. Correspondingly, the maximum number of this local box refinement was set as the same as the maximum global number of refinement. In this simulation, the local maximum number was determined as equal to 12. Meanwhile, another surface was employed as a triangle purposed to capture the effective area in both $\mathrm{x}$ and $\mathrm{y}$ directions, where the Kelvin waves will appear. Furthermore, the effective domains for the CFD simulation in deep water conditions or infinite water depth. Considering on less computational time, the authors apply the symmetrical computational domain model (for the demihull and the symmetrical catamaran models) and the fully computational domain for the staggered catamaran model.

Table 1. Principal dimensions of "deep-V” catamaran model.

\begin{tabular}{lc}
\hline \multicolumn{1}{c}{ Description } & Catamaran \\
\hline Length between perpendiculars, $L B P(m)$ & 1.740 \\
Breadth, $B(m)$ & 0.678 \\
Draft, $T(m)$ & 0.080 \\
Wetted surface area, WSA $\left(\mathrm{m}^{2}\right)$ & 0.5119 \\
Volume of displacement, $\nabla\left(\mathrm{m}^{3}\right)$ & 0.0272 \\
Displacement, $\Delta$ (tonnes $)$ & 10.7924 \\
\hline
\end{tabular}

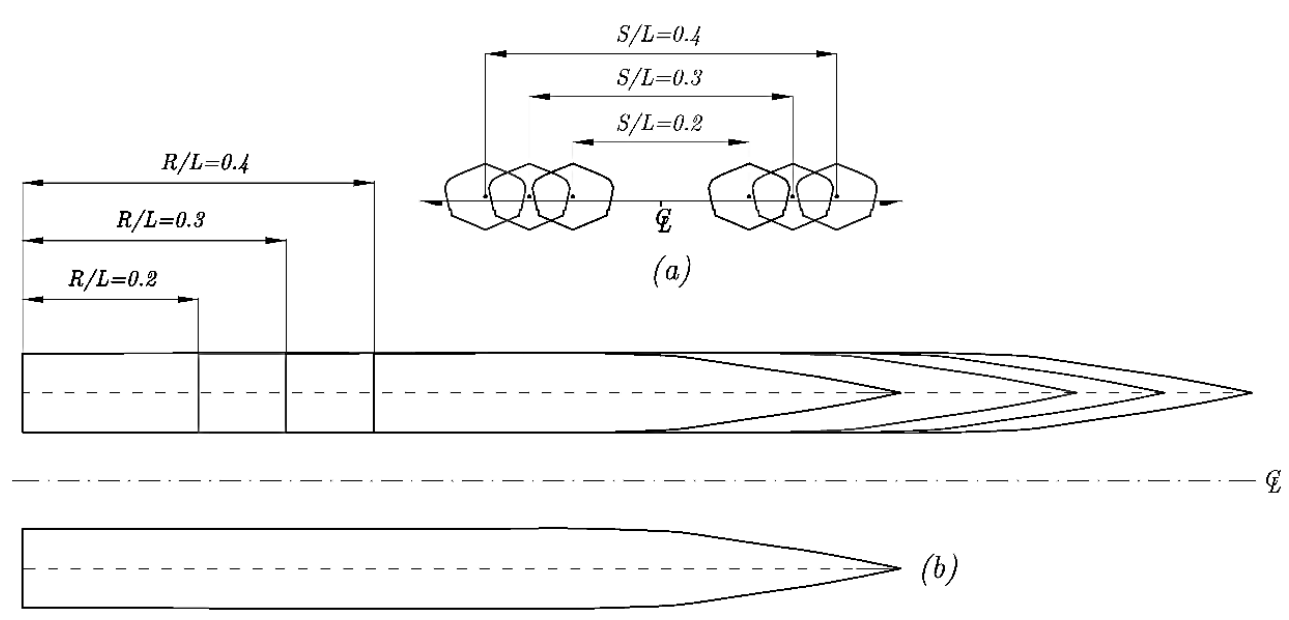

Figure 2. Simulation conditions on predicting tool resistance on a high-speed "deepV" catamaran due to: (a) effect of $S / L$ and (b) effect of $R / L$.

Referring to Table 3, the external (EXT) boundary type condition is assigned to treat velocity and pressure conditions. In addition, the boundary condition for the top of the patches domain is assigned as 'prescribed pressure'. In this mode, the pressure is imposed during computation initialisation, where the updated hydrostatic pressure is then applied. This means that the pressure is not constantly at 0 (zero) during computation but it dynamically updates due to the cell mesh moving vertically towards the free surface 
position. Concerning the boundary conditions, the demihulls surfaces are assigned as solid patches, where a wall-function condition is employed to these surfaces.

Table 2. Matrix of computational fluid dynamic simulation.

\begin{tabular}{|c|c|c|c|c|c|c|}
\hline \multirow[b]{2}{*}{$\begin{array}{l}\text { Matrix of CFD } \\
\text { Simulation }\end{array}$} & & \multicolumn{4}{|c|}{$R / L$} & \multirow{2}{*}{$\frac{\text { Froude No. }}{F r}$} \\
\hline & & 0.0 & 0.2 & 0.3 & 0.4 & \\
\hline \multirow[t]{3}{*}{$S / L$} & $\begin{array}{c}0.2,0.3 \text { and } \\
0.4\end{array}$ & - & - & - & - & $\begin{array}{c}0.5,0.6,0.7 \\
0.8,0.9 \text { and } \\
1.0\end{array}$ \\
\hline & 0.3 & $\sqrt{ }$ & $\sqrt{ }$ & $\sqrt{ }$ & $\sqrt{ }$ & $\begin{array}{c}0.5,0.6,0.7 \\
0.8,0.9 \text { and } \\
1.0\end{array}$ \\
\hline & $\begin{array}{c}0.2,0.3 \text { and } \\
0.4\end{array}$ & - & - & - & - & $\begin{array}{c}0.5,0.6,0.7 \\
0.8,0.9 \text { and } \\
1.0\end{array}$ \\
\hline
\end{tabular}

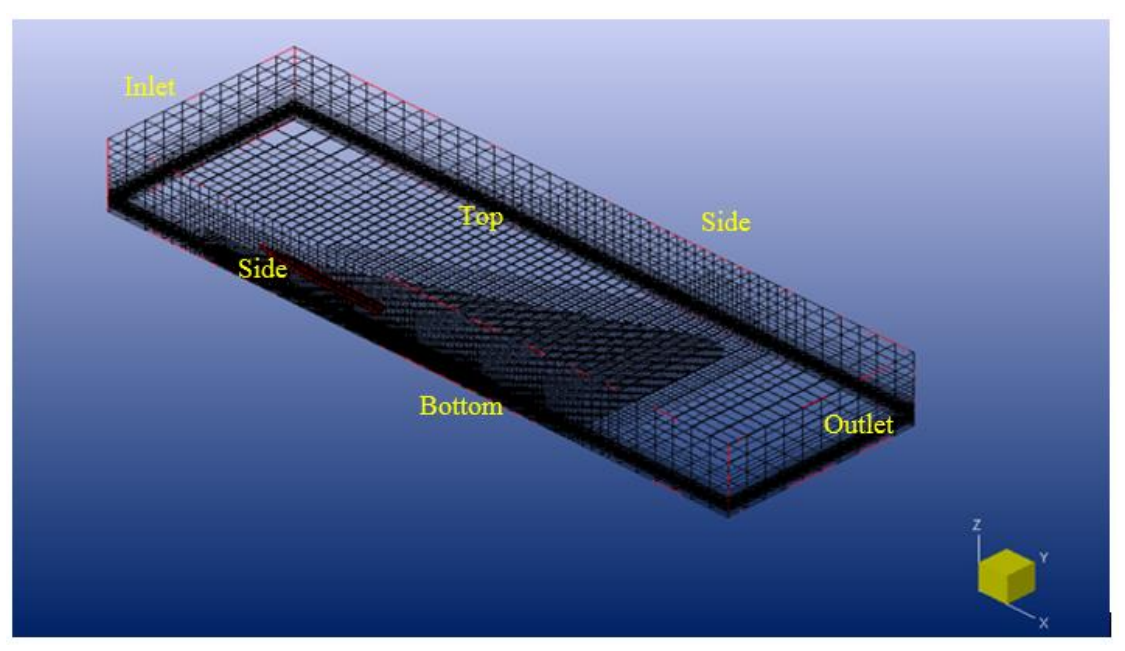

Figure 3. Boundary condition of a high-speed "deep-V" catamaran model in shallow water.

Table 3. Computational domain and boundary setting conditions

\begin{tabular}{lccc}
\hline \multicolumn{1}{c}{ Description } & Distance with respect to origin point & Type & Condition \\
\hline$X_{\min }$ (Inlet) & $1.0 L_{m h}$ & EXT & Far field \\
$X_{\max }$ (Outlet) & $3.0 L_{m h}$ & EXT & Far field \\
$Z_{\min }$ (Bottom) & $0.0964 L_{m h}$ & SOL & Wall Function \\
$Z_{\max }$ (Top) & $0.5 L_{m h}$ & EXT & Prescribed field \\
$Y_{\min }$ (Side) & $1.5 L_{m h}$ & EXT & Far field \\
$Y_{\max }$ (Side) & $1.5 L_{m h}$ & EXT & Far field \\
\hline
\end{tabular}

In accordance with the best practice guidelines for marine applications of NUMECA FINE Marine 3.1-1, the average duration of every simulation is about 70 to 80 hours (4 parallel computations with $\Delta \mathrm{t}=0.001 \mathrm{~s}$ ) on a HP Z820 Workstation PC with 
Intel(R) Xeon(R) processor ES-2690 v2 CPU @ 3.00 GHz (2 Processors) associated with the installed memory [3] of $32.0 \mathrm{~GB}$ and 64-bit operating system.

\section{Mesh Independent Study}

For the current CFD simulation, the mesh independent study of catamaran was conducted to assess a proper total number of cell meshing for the whole simulations. The results of the mesh independent study are summarised in Table $4(S / L=0.3$ and $F r=0.8)$. The meshing generation of catamaran model for the main hull block and outriggers surface is created in HEXPRESS 3.3.1. It should be noted that adequate mesh number is important to maintain numerical accuracy and steadiness in computation result, regardless of the longer CPU time. Hence, a mesh independent study is necessary to examine each of three cell meshing initial number. Table 4 refers to the mesh independent study result. The initial cell meshing of 170 in case $\mathrm{C}$ is selected from all the cases because it has reasonable accuracy of CFD solution. This can be explained by the fact that the increase of initial cell meshing number to 240 in computation was unnecessary due to insignificant influence on the computational result for total resistance.

Table 4. Mesh independent study on symmetrical catamaran.

\begin{tabular}{ccccc}
\hline Case & $\begin{array}{c}\text { Initial Number of } \\
\text { Meshing }\end{array}$ & $\begin{array}{c}\text { Total Number of cell } \\
\text { in initial mesh }\end{array}$ & $\begin{array}{c}\text { Number of Cell } \\
\text { Meshing }\end{array}$ & $\begin{array}{c}\text { Total } \\
\text { Resistance }(\mathrm{N})\end{array}$ \\
\hline A & $5 \times 4 \times 2$ & 40 & 823779 & 13.9382 \\
B & $6 \times 5 \times 3$ & 90 & 1121405 & 13.8204 \\
C & $7 \times 5 \times 2$ & 170 & 2055700 & 13.6449 \\
D & $20 \times 6 \times 2$ & 240 & 2649747 & 13.6517 \\
\hline
\end{tabular}

\section{RESULTS AND DISCUSSION}

\section{CFD Simulation Results}

A series of resistance prediction through high-speed "deep-V" catamaran model in shallow water were successfully conducted by using CFD simulation approach. The CFD simulations were performed on various configuration models, i.e. symmetrical catamaran and staggered catamaran models. The simulation results are presented, along with a discussion of lateral separation effects and longitudinal staggered ratios on total resistances and coefficients characteristics for the symmetrical and the staggered catamaran models. [26] stated that the interaction between the demihulls of a catamaran depends strongly on both the hull separation and Froude number. The interaction between hulls gave a big impact on the total resistance and total resistance coefficient. For example, two different resistance simulations of the symmetrical catamaran and the staggered catamaran models of Froude number of 1.0 are shown in Figure 4.

\section{Effect of Lateral Separation Ratio (S/L)}

Regardless of the lateral separation ratios, the results showed that the subsequent increase of Froude number from 0.5 to 1.0 was proportional with the total resistance, as displayed in Figure 5(a). Comparing the results on $\mathrm{S} / \mathrm{L}$ ratios of 0.2 and 0.4 versus Froude number, the lateral separation ratio of $S / L=0.3$ showed the maximum increment of $R_{T}$ of about $22.4 \%$ and $18 \%$ as $F r$ increased from 0.5 to 0.6 and 0.9 to 1.0 , respectively. Referring to Figure 5(b), the total resistance coefficient had generally reduced as the $F r$ increased, which is similarly well-reported by [27]. In the case of $S / L$ ratios of 0.2 , it showed that 
the highest decrement of the total resistance coefficient was about $13.2 \%$, since the increase of $F r=0.5$ to 0.6 . In addition to the increase of various $\mathrm{S} / \mathrm{L}$ ratios, the results showed that the increase in $\mathrm{S} / \mathrm{L}$ from 0.2 to 0.3 and 0.3 to 0.4 had reduced the total resistance by $3.1 \%$ and $2.2 \%$, respectively. These results can be validated by the study from [11] who stated that the resistance decreased as the hull separation ratio increased. It can be concluded that the increase of $\mathrm{S} / \mathrm{L}$ ratios in shallow water condition resulted in almost negligible effect on the total resistance of the high speed "deep-V" symmetrical catamaran. In other words, the magnitude of her total resistance was relatively independent, subjected to the lateral separation ratios. As compared to the increase of $\mathrm{S} / \mathrm{L}$ from 0.3 to 0.4 , the increase of $\mathrm{S} / \mathrm{L}$ of 0.2 to 0.3 dealt with a more significant reduction of $\mathrm{C}_{\mathrm{T}}$ by $3.4 \%$. The detailed results of the resistance prediction for the high-speed "deepV" symmetrical catamaran is summarised in Table 5. Based on these CFD simulation results, it was concluded that the total resistance coefficient $\left(\mathrm{C}_{\mathrm{T}}\right)$ depended on the lateral separation ratios, where any increase in $S / L$ ratios had caused the proportional reduction in total resistance coefficient and vice versa, regardless of the $\mathrm{Fr}$. In addition to largest lateral separation ratio $(\mathrm{S} / \mathrm{L}=0.4)$, it has dealt with less total resistance coefficient. This occurred mainly due to the less contribution of wave interference and viscous effects between the two demihulls [28].

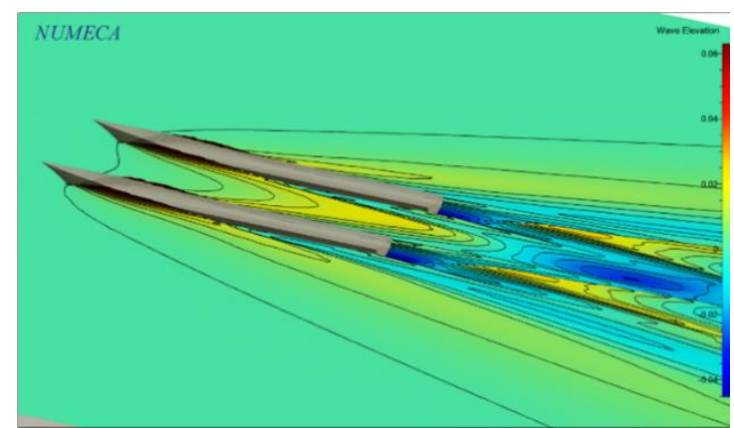

(a)

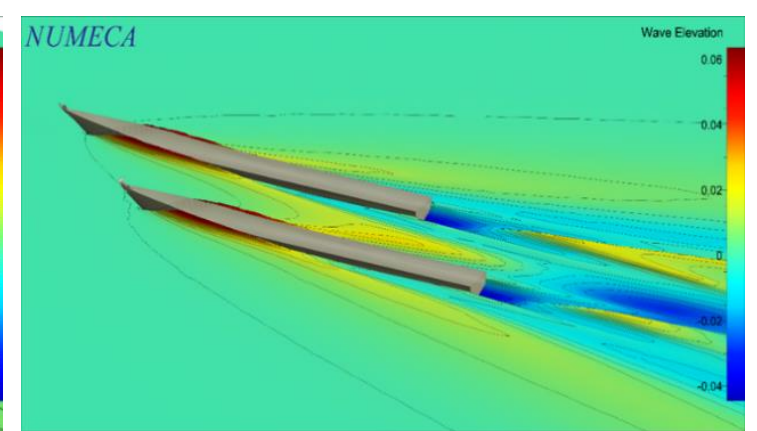

(b)

Figure 4. CFD visualisation of 3D perspective views (a) symmetrical catamaran $(S / L=0.3)$, (b) staggered catamaran, $(\mathrm{S} / \mathrm{L}=0.3$ and $R / L=0.3)$.

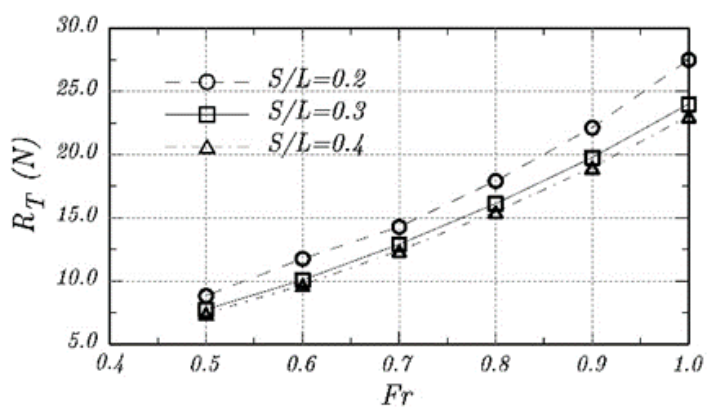

(a)

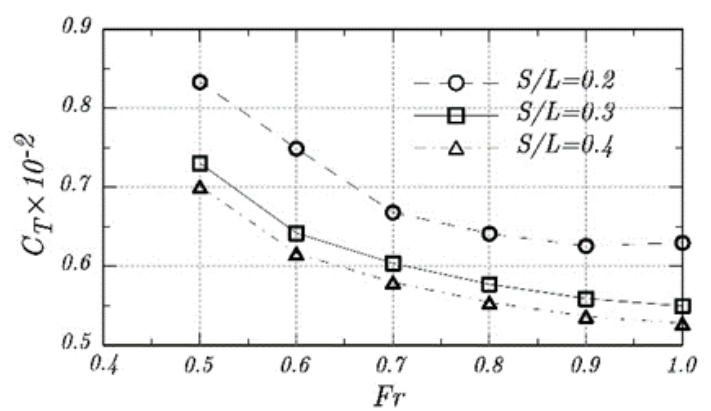

(b)

Figure 5. Total resistance (a) and total resistance coefficient (b) of high-speed "deepV" catamaran at various $S / L$ ratios versus $F r$.

Figure 6 shows the characteristic of wave pattern surrounding the high-speed "deepV" catamaran in shallow water. As seen in Figure 6 (a), the CFD simulation results showed that the highest resistance coefficient value at $\mathrm{Fr}=0.5$ occurred due to unfavourable interference factor represented by the higher wave crest in the inner region between the two demihulls (dark red color), as also presented in Figure 6(b) and Figure 
6(c). As a result, the frictional/viscous resistance had proportionally increased. However, with further increase of Fr to 1.0, the interference factor was prone to decrease or even be omitted as displayed in Figure 6(d), Figure6(e) and Figure 6(f), as also reported by Molland et al. [11]. Similar to what was reported by [29] this occurrence might be due to the favourable factor which resulted in the subsequent reduction of total resistance coefficient. It is convenient to explain here that the existence of the favourable interference factor has led to an attenuation of the viscous and pressure resistances. Through the wave pattern characteristics, the CFD simulation in Figure 6(f) showed that the wave trough that was close to the bow had reduced, which was basically proportional to the hydrodynamic pressure field and velocity gradient of the wave interference around the hull.

Table 5. Total resistance of high-speed "deep-V" symmetrical catamaran at various $S / L$ ratios.

\begin{tabular}{ccccccc}
\hline Froude & \multicolumn{2}{c}{$S / L=0.2$} & \multicolumn{2}{c}{$S / L=0.3$} & \multicolumn{2}{c}{$S / L=0.4$} \\
\cline { 2 - 7 } No. & $R_{T}(N)$ & $C_{T}$ & $R_{T}(N)$ & $C_{T}$ & $R_{T}(N)$ & $C_{T}$ \\
$F r$ & & & & & & \\
\hline 0.5 & 7.056 & 0.006460 & 6.771 & 0.006204 & 6.636 & 0.006080 \\
0.6 & 8.973 & 0.005710 & 8.720 & 0.005549 & 8.543 & 0.005436 \\
0.7 & 11.462 & 0.005358 & 11.003 & 0.005144 & 10.821 & 0.005059 \\
0.8 & 14.399 & 0.005154 & 13.645 & 0.004884 & 13.486 & 0.004827 \\
0.9 & 17.467 & 0.004940 & 16.853 & 0.004766 & 16.554 & 0.004681 \\
1.0 & 21.249 & 0.004867 & 20.550 & 0.004707 & 20.159 & 0.004618
\end{tabular}

a) $F r=0.5$
b) $F r=0.6$

Figure 6. Characteristics of wave pattern and free surface elevation on high-speed "deep-V" symmetrical catamaran at various Froude number with $\mathrm{S} / \mathrm{L}=0.3$.

\section{Effect of Froude Number ( Fr ) on Longitudinal Staggered Catamaran}

The effect of various $F r$ on the resistance behaviour of the high-speed "deep-V" catamaran with staggered hull configuration are displayed in Figure 7. The results revealed that the subsequent increase in $F r$ from 0.5 to 1.0 was proportional to total resistance $\left(\mathrm{R}_{\mathrm{T}}\right)$ and inversely proportional to total resistance coefficient $\left(\mathrm{C}_{\mathrm{T}}\right)$ as seen in Figure7(a) and Figure7(b), respectively. The CFD simulation results of $\mathrm{R}_{\mathrm{T}}$ and $\mathrm{C}_{\mathrm{T}}$ for the high-speed "deep-V" staggered catamaran model are summarised in Table 6 . In the case 
of $R / L$ ratio of 0.3 , it was noted that the highest increment of $\mathrm{R}_{\mathrm{T}}$ was about $21 \%$ as $\mathrm{Fr}$ increased from 0.6 to 0.7 . Based on the CFD simulation results, the longitudinal staggered separation ratio $(\mathrm{R} / \mathrm{L}=0.3)$ with $\mathrm{S} / \mathrm{L}=0.3$ showed the maximum $C_{T}$ increment of about $14 \%$ as $F r$ increase from 0.5 to 0.6 . As for the increase in $F r$ from $F r=0.9$ to 1.0 , although the value of $\mathrm{C}_{\mathrm{T}}$ was increased, the increment was still insignificant by $1.5 \%$. This is because the favourable factor interference corresponded to conditions where the wave system tend to coincide in cancelling each other out at the inner region [28].

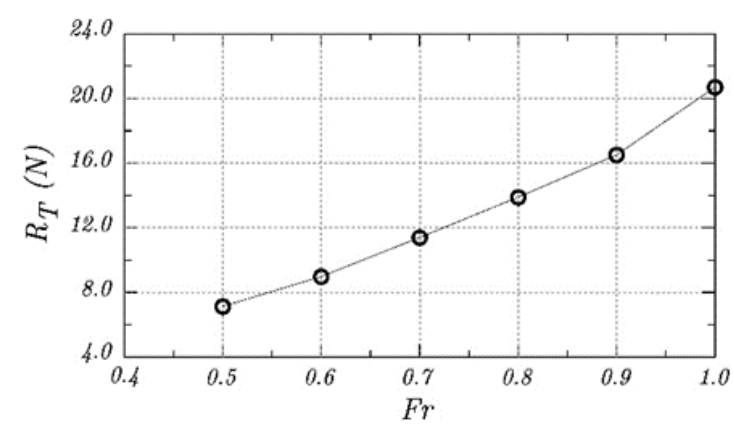

(a)

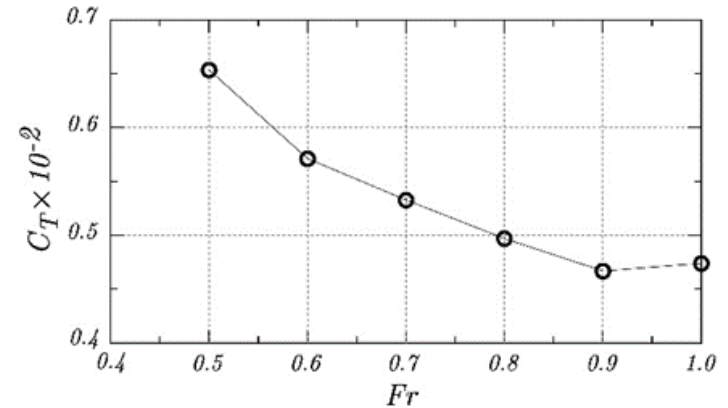

(b)

Figure 7. Total resistance (a) and total resistance coefficient (b) of high-speed "deep-V" staggered catamaran $(R / L=0.3)$ at various Froude number.

Table 6. Total resistance of high-speed "deep-V" staggered catamaran at various $\mathrm{Fr}$ $(S / L=0.3, R / L=0.3)$.

\begin{tabular}{ccc}
\hline Froude No. & \multicolumn{2}{c}{$R / L=0.3$} \\
\cline { 2 - 3 }$F r$ & $R_{T}(N)$ & $C_{T}$ \\
\hline 0.5 & 7.131 & 0.00653 \\
0.6 & 8.975 & 0.00571 \\
0.7 & 11.393 & 0.00532 \\
0.8 & 13.885 & 0.00499 \\
0.9 & 16.508 & 0.00467 \\
1.0 & 20.691 & 0.00474 \\
\hline
\end{tabular}

Figure 8 shows the interference factor presented in the form of wave pattern characteristics on the total resistance of the high-speed "deep- $V$ " catamaran with staggered hull configuration at the various $F r$. It was observed that further increase of $F r$ had possessed a lower interference factor, which was proportional with the subsequent reduction of the total resistance coefficient. For $\mathrm{Fr}=0.5$ and $\mathrm{Fr}=0.6$, the interference factor in the staggered catamaran had strongly affected the total resistance coefficient. Referring to Figure 8(a), Figure8(b) and Figure8(c), respetively, this occurred due to decrease in wave crest (free surface wave elevation) in the inner region (dark red color). Furthermore, the interference factor had apparently reduced and even disappeared as Fr became higher at 0.7 . This can be explained by observing the viscous magnitude and pressure resistances were prone to decrease along the inner region of the two demihulls, which worked to diminish the total resistance coefficient. In can be concluded that the wave system factor in the higher Fr had a relatively small effect on the interference factor, as displayed in Figure 8(c), Figure8(d) and Figure 8(e), respectively. 


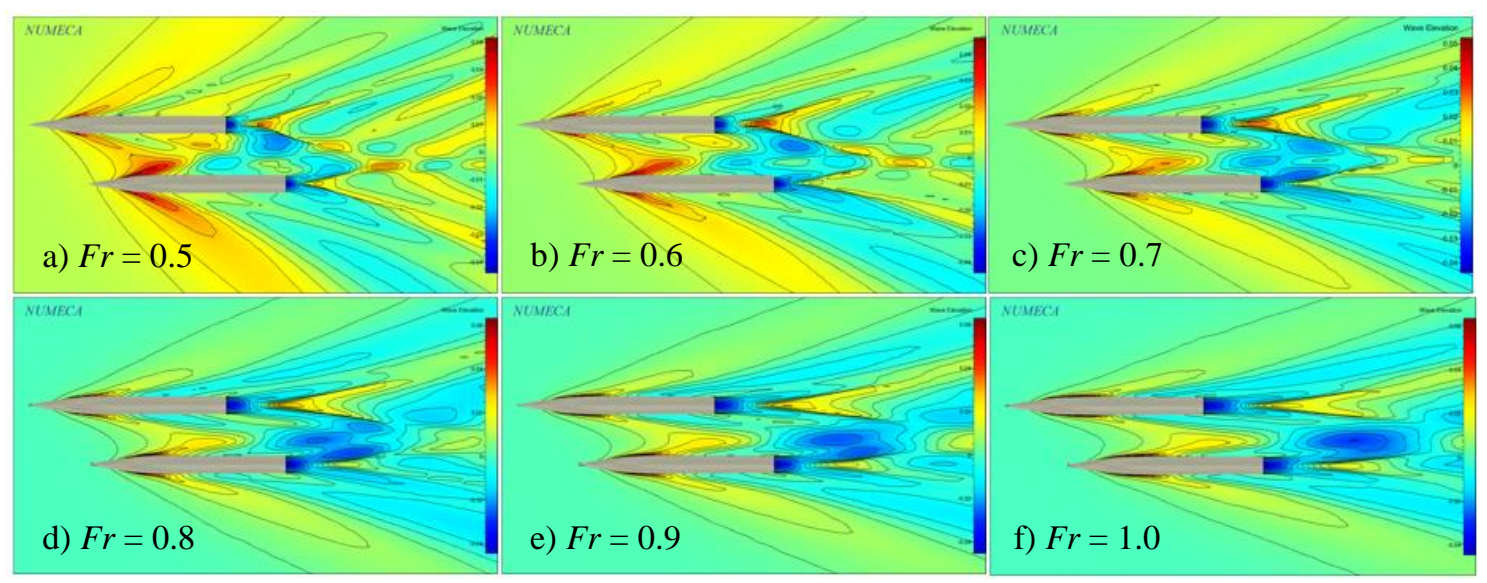

Figure 8. Characteristics of wave pattern and free surface elevations on high-speed "deep-V" catamaran at various Froude numbers $(S / L=0.3)$.

\section{CONCLUSIONS}

The CFD investigation on the total resistance coefficients of the high-speed "deep-V" catamaran in shallow water was successful. The effect of symmetrical and staggered model of the high-speed "deep-V" catamaran on the total resistance was accordingly examined at a wide range of $\mathrm{Fr}$. The computation results are drawn as follows:

i) Regardless of $S / L$ ratios, the subsequent increase of $F r$ was proportional with the increase of high speed "deep-V" catamaran total resistance, where the maximum increment reached by $22 \%$ with the increase of $F r$ from 0.5 to 0.6 for $S / L=0.3$ and $S / L=0.4$. These occurred due to the nonlinear boundary layer between two demihulls had increased due to the reduction of the wave trough.

ii) In contrast, the increase of lateral separation ratio dealt with less total resistance coefficient, where the sufficient reduction of $C_{T}$ was about $13 \%$ as the increase of $F r$ from 0.5 to 0.6 for $S / L=0.2$. These trend concluded that the total resistance coefficient depended on the lateral separation ratio.

iii) Regardless of $R / L$ ratios, the results showed that the subsequent increase of $F r$ number from 0.5 to 1.0 was also proportional to the total resistances, where the maximum $R_{T}$ increase was about $21 \%$, as $F r$ increase from 0.6 to 0.7 with $S / L=$ $0.3, R / L=0.3$.

iv) In general, the $R / L$ ratios has led to sufficient reduction of $C_{T}$ by $14 \%$ as $F r$ increased from 0.5 to 0.6 . The reason for this conjecture is that the longitudinal staggering propagated an unfavourable interference due to the wave interference between two demihulls.

Referring to the above results, the increase in $\mathrm{S} / \mathrm{L}$ and $\mathrm{R} / \mathrm{L}$ ratios had similar effects to the total resistance and total resistance coefficient characteristics with respect to the subsequent increase of $\mathrm{Fr}$. In addition to this CFD simulation, these results are very useful as preliminary data for the ship resistance, which is primarily required to accurately predict the ship powering.

\section{ACKNOWLEDGEMENTS}

The authors wish to greatly thank for the special financial support from School of Ocean Engineering, Universiti Malaysia Terengganu. 


\section{REFERENCES}

[1] Kenevissi F, Atlar M, Mesbahi E. A New-generation Motion-control System for Twin-hull Vessels using a Neural Optimal Controller. Marine Technology. 2003;40:168-80.

[2] Hadler J, Lee C, Birmingham J, Jones H. Ocean catamaran seakeeping design, based on the experiments of USNS HAYES. 1974.

[3] Varyani KS, Gatiganti RM, Gerigk M. Motions and slamming impact on catamaran. Ocean Engineering. 2000;27:729-47.

[4] Prakash S, Chandra B. Numerical estimation of shallow water resistance of a river-sea ship using CFD. International Journal of Computer Applications. 2013;71.

[5] Mucha P, Deng G, Gourlay T, Moctar E, Ould B. Validation Studies on numerical prediction of ship squat and resistance in shallow water. 4th MASHCONInternational Conference on Ship Manoeuvring in Shallow and Confined Water with Special Focus on Ship Bottom Interaction2016. p. 122-33.

[6] Jachowski J. Assessment of ship squat in shallow water using CFD. Archives of Civil and Mechanical Engineering. 2008;8:27-36.

[7] Saha GK, Suzuki K, Kai H. Hydrodynamic Optimization of ship hull forms in shallow water. Journal of Marine Science and Technology. 2004;9:51-62.

[8] Havelock T. The effect of shallow water on wave resistance. Proceedings of the Royal Society of London Series A, Containing Papers of a Mathematical and Physical Character. 1922;100:499-505.

[9] Moraes H, Vasconcellos J, Latorre R. Wave resistance for high-speed catamarans. Ocean Engineering. 2004;31:2253-82.

[10] Insel M, Molland A. An investigation into the resistance components of high speed displacement catamarans. 1992.

[11] Molland A, Wellicome J, Couser P. Resistance experiments on a systematic series of high speed displacement catamaran forms: variation of length-displacement ratio and breadth-draught ratio. 1994.

[12] Sahoo PK, Doctors LJ, Pretlove L. CFD Prediction of the wave resistance of a catamaran with staggered demihulls. 2006.

[13] Utama I. Investigation of the viscous resistance components of catamaran forms. 1999.

[14] Utama I, Molland M. Experimental and numerical investigations into catamaran viscous resistance. 2001.

[15] Muller-Graf B, Radojcic D, Simic A. Resistance and propulsion characteristics of the vws hard chine catamaran hull series' 89. SNAME Transactions. 2002;110:129.

[16] Armstrong T. The effect of demihull separation on the frictional resistance of catamarans. FAST 2003, Ischia, Italy. 2003.

[17] Menter F. Influence of freestream values on k-omega turbulence model predictions. AIAA Journal. 1992;30:1657-9.

[18] Menter F. Performance of popular turbulence models for attached and separated adverse pressure gradient flow. AIAA Journal. 1992;30:2066-72.

[19] Menter F. Zonal two-equation $\mathrm{k}-\omega$ turbulence models for aerodynamic flows. AIAA 24th Fluid Dynamics Conference. 1993.

[20] Menter FR. Two-equation eddy-viscosity turbulence models for engineering applications. AIAA Journal. 1994;32:1598-605. 
[21] Spalart PR, Allmaras SR. A One equation turbulence model for aerodynamic flows. Recherche Aerospatiale-French Edition. 1994:5-.

[22] Baldwin BS, Barth TJ. A One-equation Turbulence transport model for high reynolds number wall-bounded flows. National Aeronautics and Space Administration, Ames Research Center; 1990.

[23] Menter F, Rumsey C. Assessment of two-equation turbulence models for transonic flows. Fluid Dynamics Conference. 1994:2343.

[24] Soo SL, Antar, M. T., Aspinwall, D. K., Sage, C., Cuttell , M., Perer, R. \& Winn, A. J. The effect of wire electrical discharge machining on the fatigue life of Ti6Al-2Sn-4Zr-6Mo aerospace alloy. Procedia CIRP. 2013;6:215 - 9.

[25] ITTC. Report of the performance committee. 1957.

[26] Broglia R, Jacob B, Zaghi S, Stern F, Olivieri A. Experimental investigation of interference effects for high-speed catamarans. Ocean Engineering. 2014;76:7585.

[27] Castiglione T, He W, Stern F, Bova S. URANS simulations of catamaran interference in shallow water. Journal of Marine Science and Technology. 2014;19:33-51.

[28] Fitriadhy A, Lim PS, Jamaluddin A. CFD Investigation on total resistance coefficient of symmetrical and staggered catamaran configurations through quantifying existence of an interference factor. In: International Conference on Ships and Offshore Structures. Hamburg, Germany; 2016.

[29] Souto-Iglesias A, Zamora-Rodríguez R, Fernández-Gutiérrez D, Pérez-Rojas L. Analysis of the wave system of a catamaran for CFD validation. Experiments in Fluids. 2007;42:321-32. 